\title{
The Agulhas system as a key region of the global oceanic circulation
}

\section{Arne Biastoch and Claus Böning, Ocean Circulation and Climate Dynamics}

- Theory \& Modelling

The Agulhas system transports warm and salty waters from the Indian to the Atlantic Ocean and therefore acts as a key element in the global oceanic circulation. Studies have shown that mesoscale processes are not only important for the correct description of the circulation around South Africa itself but also for its impact on the Gulf Stream system in the North Atlantic.

\begin{abstract}
We flow of warm and salty waters from the Indian Ocean to the Atlantic Ocean around the southern tip of Africa is an important element of the global ocean circulation. Under present climate conditions this interoceanic flux, the Agulhas leakage, provides the bulk of the upper, warm limb of the overturning circulation in the Atlantic Ocean. Parts of this water later feed into the Gulf Stream system of the North Atlantic that is responsible for the mild climatic conditions in Europe.
\end{abstract}

What factors determine the intensity of Agulhas leakage? How will it react to changes in the atmospheric conditions, such as a southward shift in the westerlies which has been indicated by scenario calculations of the recent Intergovernmental Panel on Climate Change (IPCC) report? And, what would be the consequences for the Atlantic overturning and the Gulf Stream system?

To examine the role of Agulhas leakage in the global oceanic circulation, an innovative ocean modeling programme has been set up that advances new methodologies developed in international cooperation with French and South African colleagues, based on the European model system NEMO. Since the key el- ements of the circulation in the Agulhas system are dominated by mesoscale processes (Fig. 1) it uses a high-resolution grid for the greater Agulhas region. This regional model is nested in a global ocean/sea ice model of coarser resolution and forced by observed atmospheric conditions during the period 1958 - 2004. Due to an effective and novel "two-way" nesting approach this system for the first time allows us to unravel how the explicitly simulated mesoscale variability in the Agulhas dynamics feeds back to the global ocean.

Due to the high resolution and its state-ofthe-art configuration the Agulhas nest simulates all mesoscale features of the current system around South Africa with great verisimilitude (Fig. 2): A strong western boundary current, the Agulhas Current, transports the warm and salty water southward in the Indian Ocean. South of Africa it abruptly turns back into the Indian Ocean, while shedding enormous rings, which transport heat and salt as pulsating elements into the Atlantic Ocean. The simulation also includes small-scale upstream perturbations such as Mozambique eddies as seen in satellite observations. The explicit simulation of those perturbations allows assessing their possible

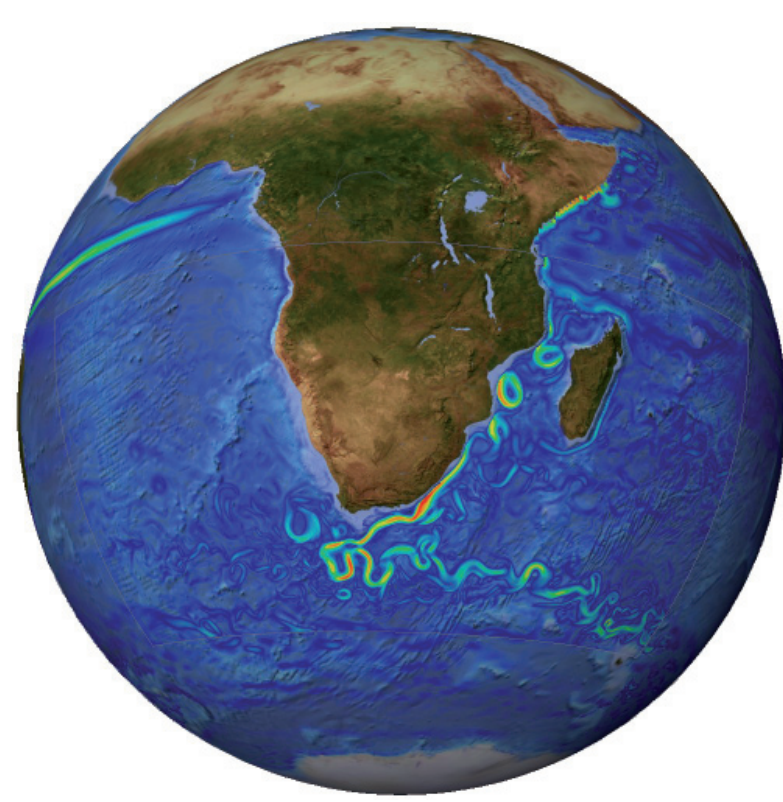

Figure 1: Circulation around South Africa.

The Agulhas Current flows along the east coast of South Africa, retroflecting back into the Indian Ocean south-west of Cape Town. During this process Agulhas rings are cut off and drift into the Atlantic Ocean.

triggering effect on the Agulhas leakage.

The role of mesoscale processes in the net volume transfer between the Indian and Atlantic Ocean was addressed by comparing the reference simulation with an experiment in which the same global model was integrated without the high-resolution nest in the Agulhas regime. The solution of this non-eddying model (Fig. 2a) portrays the inter-oceanic exchange as a continuation of parts of the Agulhas Current as a smooth 
Scientific Highlights

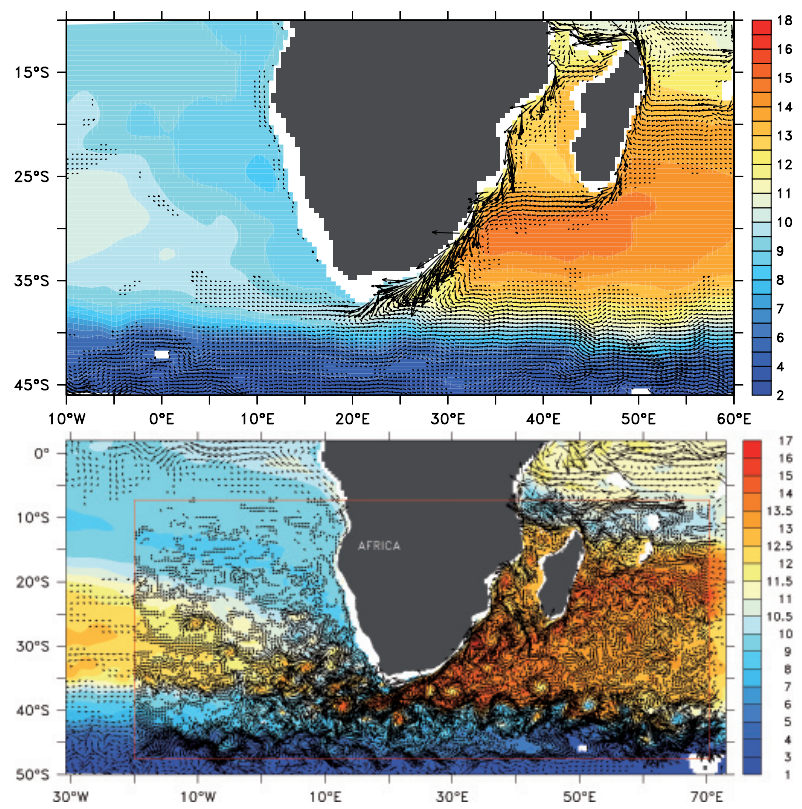

Figure 2: Water temperature and currents around South Africa. The two snapshots show temperatures and velocities at $450 \mathrm{~m}$ depth. In the (a) coarse-resolution model the Agulhas Current and the interoceanic transport appear as a broad flow of water. (b) The highresolution nest (red lines) explicitly resolves meso processes, simulating all important details necessary for a correct description of Agulhas leakage.

current, a solution typical of current climate models. In comparison to observations it strongly overestimates the net exchange from the Indian to the Atlantic Ocean. Only if mesoscale eddies are explicitly simulated, such as in the high-resolution nest (Fig. 2b), realistic interoceanic transports appear in the solution.

What is the effect of the Agulhas Current system on the large-scale circulation in the Atlantic Ocean? By comparing the cir-

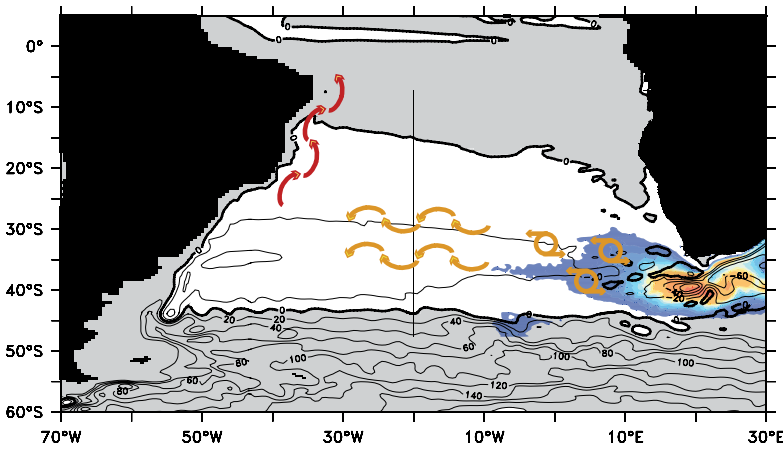

Figure 3: Schematic of the wave processes conveying Agulhas-induced anomalies in the upper limb of the overturning. The contour lines depict the mean horizontal circulation, the color information shows the eddy kinetic energy in the Agulhas region. The arrows give an illustration of the dynamic spreading of Agulhas induced variability by rings and Rossby waves (yellow) and Kelvin waves along the continental slope of South America (red) (from Biastoch et al., Nature, 2008).

culation in solutions with and without the high-resolution Agulhas nest we were able to identify an intriguing contribution of the mesoscale Agulhas dynamics on decadal current fluctuations reaching far into the North Atlantic. The dynamical signal originating south of Africa rapidly travels northward by boundary waves (Fig. 3). In the tropical and sub-tropical North Atlantic the Agulhasinduced variability has similar amplitudes as the variability introduced by sub-polar deepwater formations events, a mechanism that has been known for its climatic impact and that has been extensively studied in the past. This finding highlights the importance for studying the Agulhas regime and its associated interoceanic transport as a prominent key region of the global thermohaline circulation.

\section{IFM-GEOMAR Contributions}

Biastoch, A., C. W. Böning, and J. R. E. Lutjeharms, 2008: Agulhas leakage dynamics affects decadal variability in Atlantic overturning circulation. Nature, 456, doi:10.1038/nature07426, 489-492.

Biastoch, A., J. R. E. Lutjeharms, C. W. Böning, and M. Scheinert, 2008: Mesoscale perturbations control inter-ocean exchange south of Africa, Geophys. Res. Lett., 35, L20602, doi: 10.1029/2008GL035132.

Biastoch, A., C. W. Böning, J. Getzlaff, J.-M. Molines, and G. Madec, 2008: Mechanisms of interannual - decadal variability in the meridional overturning circulation of the mid-latitude North Atlantic Ocean, J. Climate, 21, doi: 10.1175/2008JCLI2404.1, 6599-6615.

Biastoch, A., 2008: The Agulhas Leakage: Role of Mesoscale Processes and Impact on the Atlantic Meridional Overturning Circulation, Habilitationsschrift an der Christian-Albrechts-Universität zu Kiel.

Biastoch, A., C. W. Böning, M. Scheinert, and J. R. E. Lutjeharms, 2008: The Agulhas System as a Key Region of the Global Oceanic Circulation. In: W. E. Nagel et al. (Eds): High Performance Com puting in Science and Engineering '08, Springer, 459-469.

Siedler, G. M. Rouault, A. Biastoch, B. Backeberg, C. J. C. Reason, and J. R. E. Lutjeharms, 2009: Modes of the southern extension of the East Madagascar Current, J. Geophys. Res., C01005, doi: $10.1029 / 2008$ JC004921. 